\title{
A variant limb deformity transcript expressed in the embryonic mouse limb defines a novel formin
}

\author{
Laurie Jackson-Grusby, Ann Kuo, and Philip Leder \\ Howard Hughes Medical Institute and Department of Genetics, Harvard Medical School, Boston, Massachusetts 02115 USA
}

\begin{abstract}
The formins constitute a set of protein isoforms encoded by the alternatively spliced transcripts arising from the limb deformity (ld) locus of the mouse. Mutations in this locus disrupt formation of the anteroposterior axis of the embryonic limb. Although $1 d$ transcripts are widely expressed during embryogenesis, we have identified a novel transcript that is expressed in the mesenchyme and apical ectodermal ridge of the developing limb. This pattern of expression coincides with the earliest morphological defects observed in ld mutant limb buds. Moreover, the formin encoded by this transcript bears a highly acidic amino terminus, as distinguished from the basic amino terminus encoded by other $l d$ transcripts, suggesting that it may have a distinct biochemical function.
\end{abstract}

[Key Words: Alternative splicing; apical ectodermal ridge; embryogenesis; limb development; pattern formation]

Received October 22, 1991; revised version accepted November 20, 1991.

Classic embryological manipulations combined with recent molecular analyses have established the developing limb as an important model system for elucidating the mechanisms of vertebrate pattern formation (for review, see Tabin 1991). Embryological studies, in particular, implicate reciprocal inductive interactions between the ectoderm and mesenchyme in establishing the limb pattern (Zwilling 1956a). Morphogenetic structures in both the limb ectoderm and mesenchyme are required in this process, namely, the apical ectodermal ridge (AER) and the zone of polarizing activity (ZPA). The AER is a rim of columnar epithelial cells at the distal tip of the limb bud that maintains the underlying mesenchyme in a proliferative and undifferentiated state (Saunders 1977). Patterning of the mesenchyme, or establishing the positional identity of a cell along the anteroposterior axis, has been proposed to be regulated by a morphogen released from the ZPA (Wolpert 1969), a group of mesenchymal cells at the posterior margin of the limb (Saunders and Gasseling 1968).

Loss-of-function mutations that disrupt normal limb development define a set of genes required for limb morphogenesis (Grueneberg 1963; Lyon and Searle 1989). The phenotypes of the mouse mutant $\operatorname{limb}$ deformity (ld) indicate that the $l d$ gene is essential for proper limb pattern formation (Kleinebrecht et al. 1982; Woychik et al. 1985|. Specifically, the earliest embryonic manifestations of the limb defect include incomplete AER differentiation and a marked reduction in the anteroposterior axis of $1 d$ mutant limb buds (Zeller et al. 1989). These $1 d$ mutations result in abnormal morphogenesis of both the limb and the kidney. The five known recessive $1 d$ alleles all display similar phenotypes, including fusion of distal bones of the limb, reduction in the number of digits, and a variably penetrant renal aplasia (Cupp 1960; Kleinebrecht et al. 1982; Messing et al. 1990; Woychik et al. 1985, 1990a). Cloning of the $1 d$ gene, which encodes a novel set of proteins, the formins, has identified one of the genes necessary for correct patterning of the vertebrate limb (Woychik et al. 1985, 1990b).

Because a complex array of transcripts arises from the ld gene, owing to alternative splicing and differential polyadenylation (Woychik et al. 1990b), we have sought to characterize the expression pattern of these transcripts in the developing limb. Expression of $1 d$ transcripts is observed in a wide array of adult tissues and throughout the embryo. Consistent with this RNA analysis, Trumpp et al. (this issue) have localized the chicken ld gene products by immunohistochemistry on chick embryos to the developing limb, kidney, and central nervous system. Considering the tissue-specific alternative splicing of $l d$ transcripts observed in adult mice (Woychik et al. 1990b), it is possible that these splice forms may also be expressed differentially during embryogenesis. Using a probe common to all $1 d$ transcripts, we have demonstrated previously $I d$ expression in both developing limb bud ectoderm and mesenchyme (Zeller et al. 1989). Identification of the particular splice form expressed in the developing limb would implicate its involvement in limb morphogenesis.

Here, we report the differential expression of several ld transcripts during mouse embryogenesis. As only one of these characterized splice forms is expressed in the developing limb, we have focused our further analysis on 
this form. The sequence of this transcript predicts a protein with an amino-terminal domain distinct from the formin sequences reported previously (Woychik et al. 1990b). In addition, in situ hybridization and ribonuclease protection analyses reveal expression of this transcript in both the AER and mesenchyme of the developing limb. Combined with the known alterations of $1 d$ transcripts in $1 d$ mutants (Maas et al. 1990), these data suggest a role for this particular $1 d$ gene product in normal limb development.

\section{Results}

Expression of one ld splice form in the developing $\operatorname{limb}$

To determine which $1 d$ transcripts are expressed in the developing organs affected by ld mutations, we have gen- erated transcript-specific probes from four different partial cDNA clones corresponding to splice variations (see Materials and methods; Woychik et al. 1990b). Ribonuclease protection analysis of representative adult tissue RNAs (Fig. 1A) shows coordinate expression of splice forms I, II, and III, with highest levels in testis, brain, and kidney. The tissue distribution of splice form IV is distinct from the other three transcripts, displaying qualitative or quantitative differences in expression in most tissues assayed. Expression patterns during embryogenesis, and particularly in developing limbs, were analyzed similarly using embryonic RNAs from gestational day 8.5-13.5 postcoitum (p.c.) (Fig. 1B). Again, striking differences in expression of these two classes of transcripts were observed. Splice forms I, II, and III display coordinate expression (Fig. 1A, and data not shown) that is first detectable by day 9.5 p.c. and increases in level in pro-

\section{A}
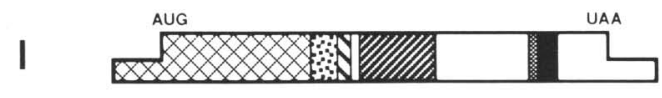

II

III

IV

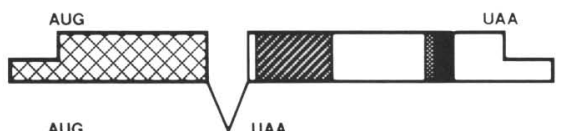

III

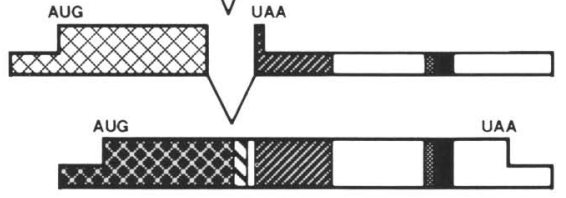

3' PROBE

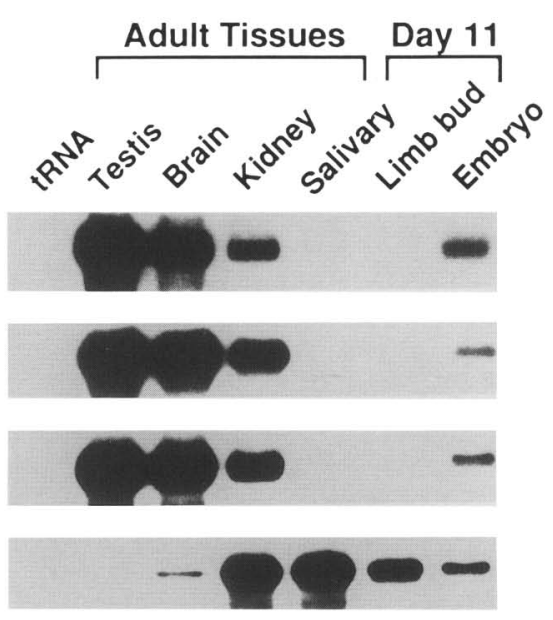

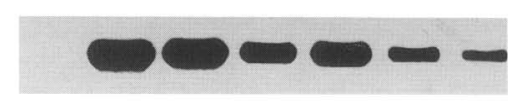

B

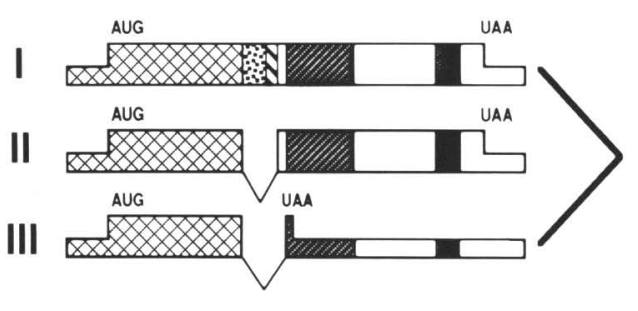

IV

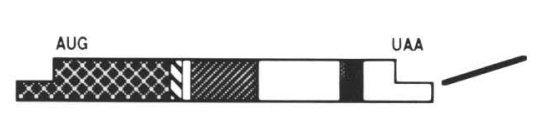

Gestational Day
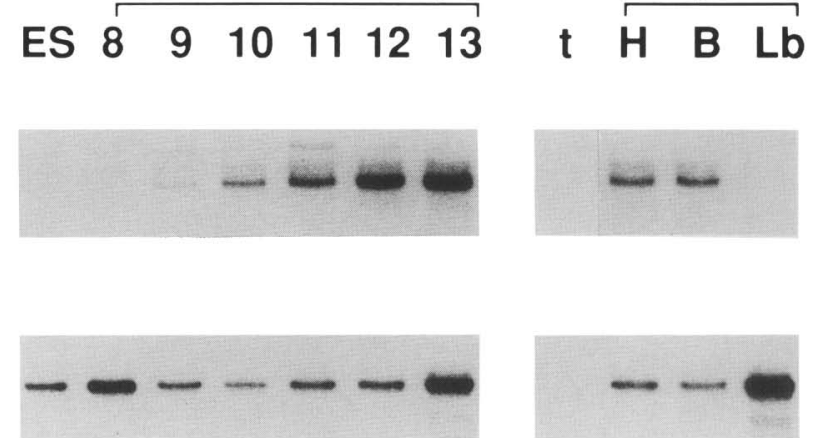
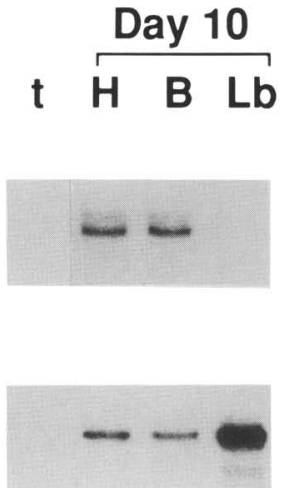

Figure 1. Ribonuclease protection analysis of the $1 d$ splice forms expressed in adult tissues and during mouse embryogenesis. Twenty micrograms of total RNA was hybridized to splice form-specific riboprobes (for probe details, see Materials and methods) and analyzed by ribonuclease protection. The different splice forms are illustrated to schematically represent both the unique and the common exons for each transcript. (A) Embryo and limb bud RNAs were from gestational day 11.5 p.c. The bottom row indicates hybridization to a 3 ' probe that detects all $l d$ transcripts (Zeller et al. 1989). (B) ES RNA was from mouse embryonic stem cells (ES-D3; Doetschman et al. 1985) grown on gelatinized plates in the presence of leukemia inhibitory factor (1000 U/ml; Amrad) (without feeder cells). Embryonic RNAs were from gestational days $8.5-13.5$ p.c.; the actual stages are 0.5 days later than indicated by the labeling. The upper panel corresponds to protection of a probe that detects splice forms I, II, and III; the lower panel corresponds to protection of the splice form IV probe. (H) Head; (B) body without limbs. 
gressively older embryos. In contrast, splice form IV is present at moderate levels much earlier in development than the other three forms, for example, as seen in day 8.5 p.c. embryos. In addition, this transcript is present in undifferentiated embryonic stem cells, which may reflect the in vivo expression of this splice form at earlier stages. However, the most notable difference in expression is in the developing limb, where only splice form IV is detected in limb buds dissected at days 10.5 and 11.5 p.c. (Fig. 1A,B). These early stages of limb development precede the formation of the cartilagenous skeletal elements (detailed by Martin 1990) and correspond to the stages when morphological defects are apparent in $1 d$ mutants (Zeller et al. 1989). The sole expression of splice form IV in the limb during these stages led us to focus on cloning the $5^{\prime}$ end of this transcript and refining our analysis of its expression pattern.

\section{Isolation of $\mathrm{ld}$ cDNA clones from embryonic limb buds}

To complete the characterization of the splice form IV limb transcript, we prepared and screened a cDNA library from day 11.0 to day 11.5 p.c. limb buds. Random hexamer-primed first-strand synthesis was used to enrich for clones containing $5^{\prime}$ ends of the large 13-, 7-, and 5-kb $1 d$ transcripts (Woychik et al. 1990b). A library of $5 \times 10^{5}$ primary clones was screened with a DNA fragment from the $5^{\prime}$ end of clone 4 (for details, see Materials and methods; Woychik et al. 1990b). This screen yielded four additional overlapping cDNA clones (for details, see legend to Fig. 2). The sequence of these cDNAs encodes a novel isoform of the set of $l d$ gene products described previously, the formins (Woychik et al. 1990b). The entire novel portion of this $5^{\prime}$ cDNA sequence is contained within one exon (boxed in Fig. 2) that encodes a unique 457-amino-acid amino-terminal domain, as determined by sequence comparison with a corresponding genomic clone (described below). The composite 4241-bp sequence of the cDNA clones with the deduced 1206amino-acid open reading frame (ORF) is presented in Figure 2. Apart from the carboxy-terminal region common to formins I, II, and IV, this sequence does not display any significant similarities to sequences entered in the GenBank data base as of this writing. An obvious biochemical function of this formin is not apparent from its primary sequence. However, there is one notable distinction between the two different amino-terminal formin sequences. The splice form IV amino-terminal domain is acidic (calculated pI 4.5, calculated charge at $\mathrm{pH}$ $7.0=-30$ ), whereas the amino-terminal domain common to formin isoforms I, II, and III is basic (calculated pI 9.8 , calculated charge at $\mathrm{pH} 7.0=+18$ ). Such differences suggest that these formins may have distinct functions.

Given the structural complexity of the $1 d$ transcripts, we wanted to determine whether the composite sequence shown in Figure 2 represents the only splice form containing this $5^{\prime}$ sequence. Polymerase chain reaction (PCR) amplification of embryonic and adult tissue first- strand cDNA carried out using an oligonucleotide primer from the $3^{\prime}$ end of this new exon and primers from progressively $3^{\prime}$ exons did not identify any additional splice forms (data not shown). Because major differences in the lengths of $l d$ transcripts result from differential polyadenylation (Woychik et al. 1990b), more subtle size differences between potential splice forms could be detected by conferring a uniform $3^{\prime}$ end on all $1 d$ transcripts. This was done with RNase $\mathrm{H}$ cleavage of RNA after hybridization to a DNA fragment near the $3^{\prime}$ end of the coding region (represented by the solid box in the diagram in Fig. 31. Northern analysis of this uniformly cleaved RNA from salivary gland was hybridized with probes specific for the splice form IV $5^{\prime}$ exon (Fig. 3, probe A) or the common $3^{\prime}$ region (Fig. 3, probe B). Both probes detect a single RNA species of $\sim 4 \mathrm{~kb}$, in contrast to the uncleaved transcript sizes of 13,7 , and $5 \mathrm{~kb}$ (Fig. 3). Similar but less intense signals were observed from parallel samples from day 10.5 p.c. embryonic RNA (data not shown). These data confirm that the size heterogeneity of $l d$ transcripts is predominantly a result of differential polyadenylation (Woychik et al. 1990b) and demonstrate that the $5^{\prime}$ and $3^{\prime}$ regions are linked on a segment of RNA that is comparable in size to the full-length coding region. Taken together with the multiple stop codons found upstream of the initiation codon, these results indicate that the overlapping cDNAs represent the full-length ORF, although they are probably missing a portion of the $5^{\prime}$-untranslated region present in the mRNA.

\section{Genomic organization of the alternative exons}

To define the genomic organization of the alternatively spliced $1 d$ exons, we isolated cosmid clones containing some of these exons. Restriction mapping was used to define exon order, and comparative sequence analysis of the cDNAs with the genomic coding regions was used to define exon borders (Fig. 4, and data not shown). The position of two known $1 d$ mutations that disrupt the $3^{\prime}$-coding region common to all of these $I d$ transcripts is illustrated in Figure 4 (Maas et al. 1990; Woychik et al. 1990b). Splice forms I, II, and III use the most 5' aminoterminal-coding exon (the basic amino acid sequence) but splice to three different downstream exons. Splice form IV has a unique $5^{\prime}$ end that encodes the new acidic amino-terminal domain described above.

\section{Limb ectoderm and mesenchyme show differential expression of ld transcripts}

Using a probe common to all $1 d$ transcripts, $1 d$ expression has been shown previously to be fivefold higher in limb ectoderm than in limb mesenchyme (Zeller et al. 1989). Our analysis of the different $l d$ transcripts present in total limb bud RNA (Fig. 1) suggested that these results probably reflected splice form IV expression. To test this directly, we performed a similar analysis on RNAs isolated from day 10.5 (data not shown) and day 11.5 p.c. embryos, dissected limb buds, and dissociated limb ec- 


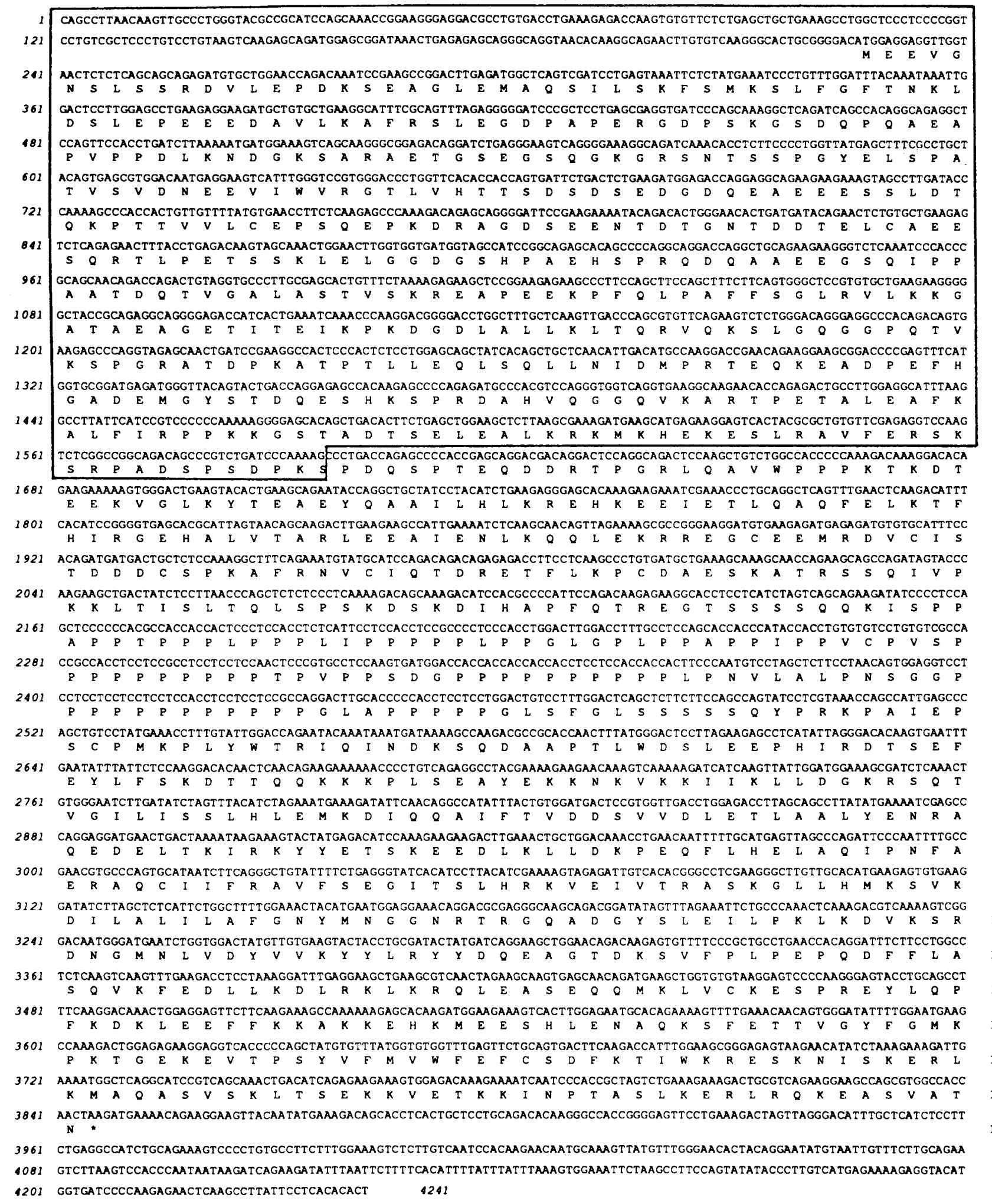

Figure 2. Nucleotide sequence and predicted amino acid sequence of the mouse $1 d$ composite limb cDNA. Nucleotide and amino acid positions are labeled at left and right, respectively. The $5^{\prime}$-boxed sequence is distinct from that reported by Woychik et al. (1990b) and includes nucleotides 1-1595 (amino acids 1-457). This unique sequence corresponds to a single exon and was confirmed from a genomic clone. The initiation codon at position 226 is preceded by termination codons in all three frames. The $5^{\prime}$ and $3^{\prime}$ borders of the overlapping cDNA clones are as follows: clone $a_{1}, 1-2169$; clone b, 787-2177; clone $c_{1} 1462-2583$; clone d, 1210-3212; and clone 4 (from Woychik et al. 1990b) 1175-4241. A 3' region of divergence from the previous ld sequence corresponds to a 108-bp segment absent between 3296 and 3297 from the $3^{\prime}$ region of clone 4 (described by Woychik et al. 1990b). 


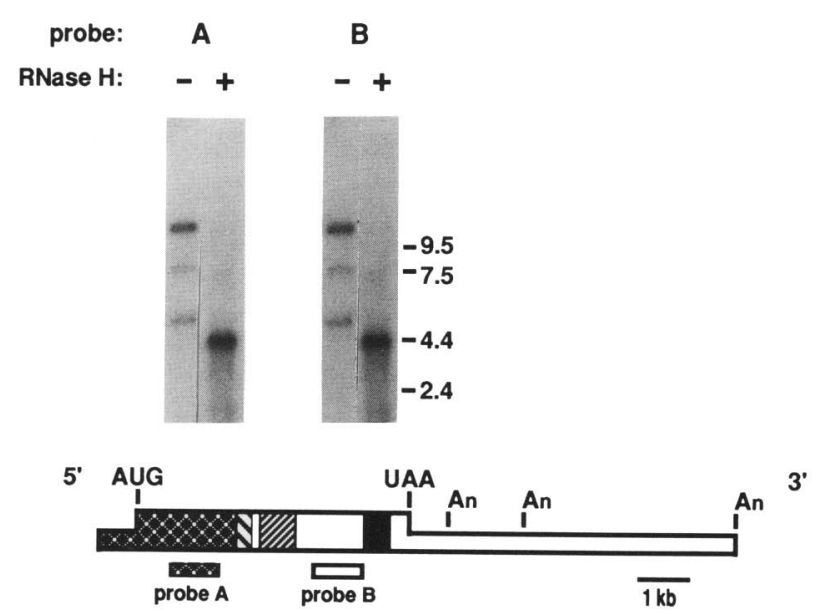

Figure 3. RNase $\mathrm{H}$ mapping defines the transcript size for the coding region. Duplicate samples containing $5 \mu \mathrm{g}$ of salivary gland poly $(\mathrm{A})^{+}$RNA were annealed to a 200 -bp DNA fragment (illustrated by the solid box $3^{\prime}$ of probe B). One sample was digested with RNase $\mathrm{H}$; both were then analyzed by Northern blot hybridization sequentially with probes $\mathrm{A}$ and $\mathrm{B}$.

toderm and mesenchyme (Fig. 5). Consistent with previous results, we observe expression of this splice form at higher levels in limb ectoderm relative to limb mesenchyme, as indicated by protection of the 300 -nucleotide fragment shown in Figure 5.

Surprisingly, we also detect expression of another potential splice form (181-nucleotide fragment; Fig. 5) exclusively in ectoderm of the limb. Three independent RNA preparations showed no expression of this fragment in limb mesenchyme by this analysis with exposures up to 14-21 days. The protected 181-nucleotide fragment corresponds to the two alternative exons included in the $3^{\prime}$ end of the probe (Fig. 5). Although these exons are also present in splice form I, ribonuclease protection data indicate that the 181-nucleotide fragment cannot represent any of the four known splice forms, including form I (Fig. 1 ; data not shown). The possibility that this fragment represents the $5^{\prime}$ end of an $1 d$ transcript can also be excluded because the genomic sequence corresponding to the $5^{\prime}$ end of the 181-nucleotide fragment contains a consensus splice acceptor and no apparent transcriptional regulatory sequences (data not shown). Consistent with the interpretation that this represents a novel splice form, we have identified one cDNA from our limb bud library with 13 unique nucleotides at its $5^{\prime}$ end, which is expressed in the expected pattern (data not shown). It is thus likely that there is at least one additional formin expressed in limb ectoderm.

\section{Limb ectoderm expression is localized to the AER}

To further refine the pattern of expression of splice form IV in the limb, we analyzed day 10.5 p.c. mouse limb buds by in situ hybridization with a probe specific for this transcript (Fig. 3, probe A). As shown in Figure 6, A and $B$, expression of this transcript is localized to the epithelial cells defining the AER in limb ectoderm and is not observed in adjacent nonridge ectoderm. Hybridization of a control sense probe to an adjacent section showed no signal in the AER, indicating the specificity of the anti-sense probe. Mesenchymal expression of this transcript, shown to be at least fivefold lower than ectodermal expression by ribonuclease protection (Fig. 5), cannot be distinguished from background hybridization in these studies (Fig. 6C). It remains possible that the mesenchymal expression of this transcript is localized, but at levels below our limit of detection.

\section{Discussion}

Reciprocal inductive interactions between the ectoderm and mesenchyme are essential for proper patterning of the vertebrate limb (Tickle 1980; Kelly and Fallon 1981; Fallon et al. 1983; see also introductory section). Inductive signals from the mesenchyme are required both for AER formation (Reuss and Saunders 1965) and maintainance (Zwilling 1956b; Zwilling and Hansborough 1956), whereas the AER provides factors that keep the underlying mesenchyme undifferentiated (Globus and Vethamany-Globus 1976) and promote mesenchymal cell pro-
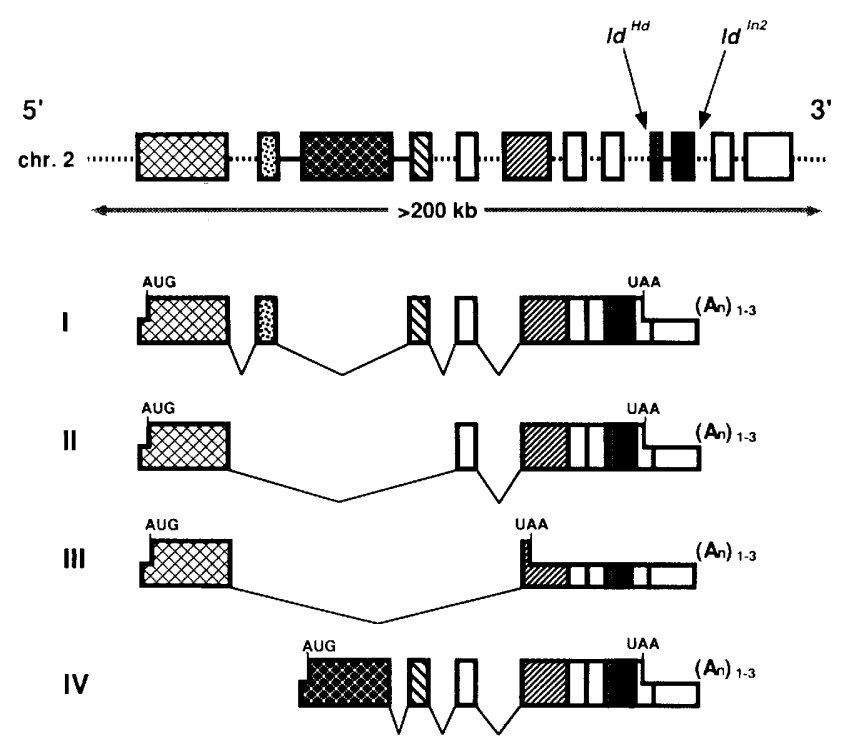

Figure 4. Structure of the $l d$ gene and its alternatively spliced transcripts. The genomic structure (top) of the 5 '-alternatively spliced exons was determined by sequence comparison of genomic and cDNA clones. Cloned exons are all indicated by unique fill patterns; coding regions not defined in genomic DNA are indicated by open boxes (L. Jackson-Grusby and R.P. Woychik, unpubl.). Uncloned intervening sequences are indicated by the broken line. Positions of the known $1 d$ mutations are marked by arrows (Maas et al. 1990; Woychik et al. 1990a,b). The exon usage of splice forms I-IV is shown beneath the genomic structure. Splice forms I, II, and III represent composite structures of cDNA clones from Woychik et al. (1990b). The sequence of splice form IV is shown in Fig. 2. The size of the exons relative to the $\sim 200-\mathrm{kb}$ locus (L. Jackson-Grusby, unpubl.) is not to scale but does approximate the relative size of the exons. 
Jackson-Grusby et al.

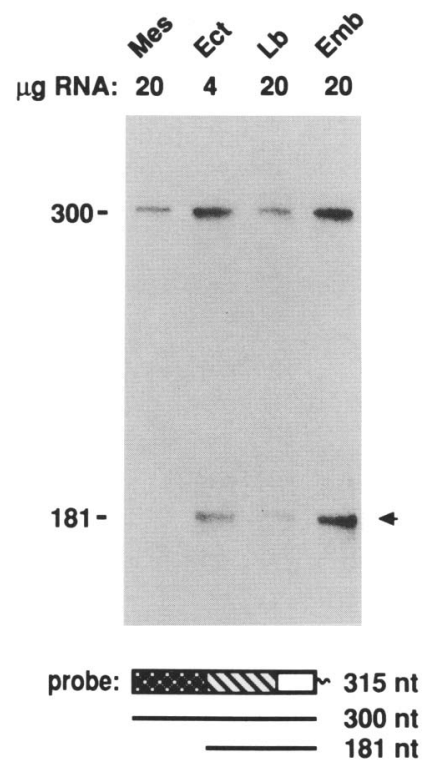

Figure 5. Differential expression of $1 d$ splice forms within the limb. Ribonuclease protection analysis of RNAs isolated from embryos (Emb), limb buds (Lb), and dissociated limb ectodermal jackets (Ect) and mesenchymal cones (Mes) all dissected between gestational days 11.0 and 11.5 p.c. The 315 -nucleotide probe contains the $3^{\prime} 119$ nucleotides from the $5^{\prime}$ exon of splice form IV plus the two adjacent alternatively spliced exons |181 nucleotides) and 15 nucleotides of polylinker. The different amounts of RNA for each sample are indicated above their respective lanes. Exposure time was 5 days, using an intensifying screen.

liferation (Solursh et al. 1981). As best described for the chick limb, the regulation of anteroposterior axis patterning requires a direct interaction between the AER and the mesenchymal ZPA (Saunders and Gasseling 1968; Tickle 1980).

An analysis of the $l d$ mutant phenotype (Zeller et al. 1989) and the molecular characterization of the $1 d$ gene products that we describe suggest roles for $l d$ in both of these morphogenetic structures. The embryonic limb phenotypes for the known recessive $1 d$ mutations include a foreshortened anteroposterior limb axis, aberrant or incomplete AER differentiation, as well as a more subtle phenotype of mesenchymal necrosis (Zeller et al. 1989). These multiple defects are most consistent with the requirement of $l d$ function in both the AER and limb mesenchyme. Both ZPA transplantation experiments and embryological analyses of other limb mutants indicate a primary role of the mesenchyme in anteroposterior axis determination (Tickle 1980). The dependence of anteroposterior limb patterning on the AER has been analyzed in studies by Rowe and Fallon (1981). By partial AER removal in chick embryos, anteroposterior limb truncations somewhat similar to those observed in $1 d$ mutants were generated. Although these operations resulted in limbs with missing and fused digits as observed in $1 d$ mutants, they failed to produce fusions of the distal bones of the limb that are well documented in $1 d \mathrm{mu}-$ tants (Kleinebrecht et al. 1982; Zeller et al. 1989). This suggests that the deficient AER resulting from 1d mutations is not the sole cause of the $1 d$ limb patterning defects, but rather, $l d$ mutations have a more direct effect on the patterning of limb mesenchyme. Splice form IV is the best candidate $1 d$ gene product for functioning in anteroposterior limb patterning, as it is the only $l d$ splice form that we have detected in limb mesenchyme (Fig. 5). Consistent with this, the expression of the chick $1 d$ gene product has been localized by immunohistochemistry to
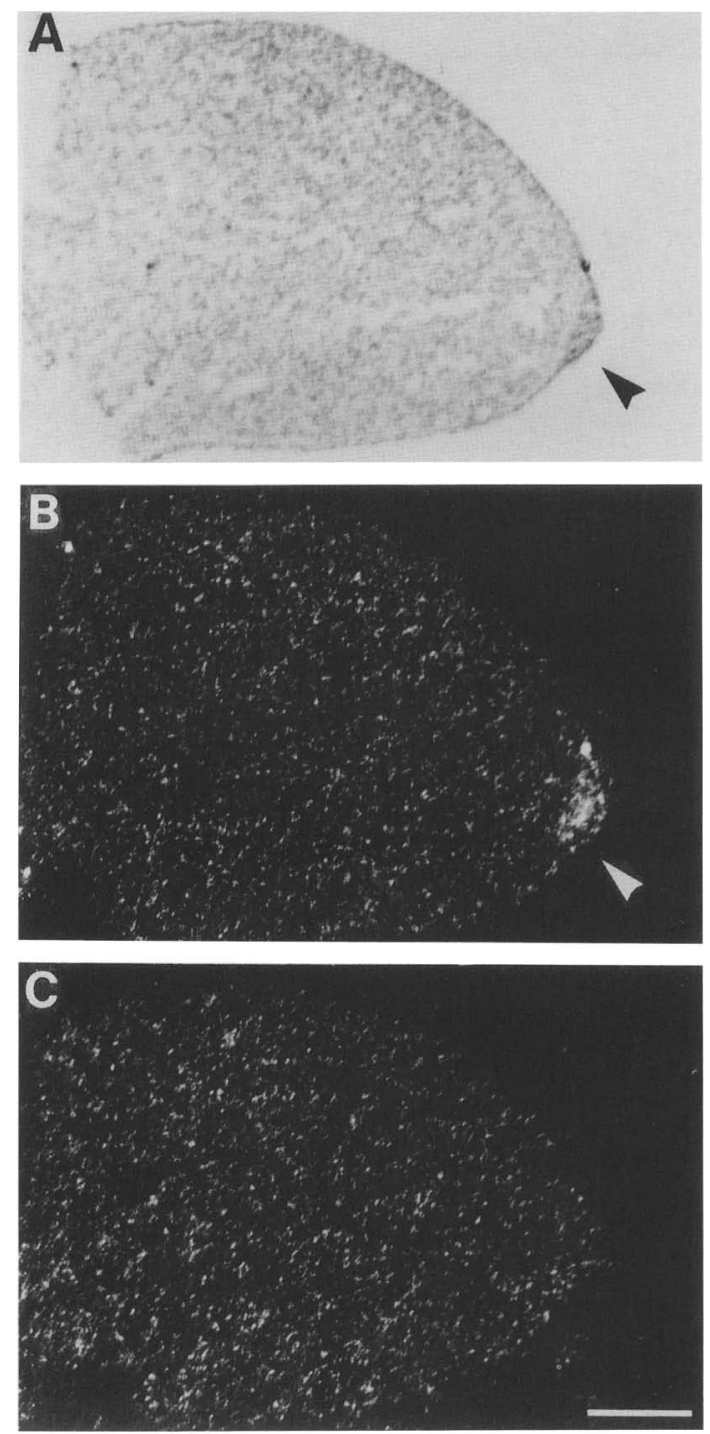

Figure 6. Expression of $l d$ splice form IV in the AER. In situ hybridization analysis of ${ }^{35} \mathrm{~S}$-labeled riboprobes from the unique 5 ' exon of splice form IV on a day 10.5 p.c. embryonic limb bud. The probes correspond to the sense and anti-sense strands of probe A (Fig. 3). (A) Bright-field illumination of a section hybridized to the anti-sense probe. $(B)$ Dark-field illumination of the section shown in $A$. The arrowhead indicates hybridization to the AER. $(C)$ Dark-field illumination of the control sense probe hybridized to an adjacent section. Exposures were for 14 days. Bar, $100 \mu \mathrm{m}$. 
coincide with the ZPA region (Trumpp et al., this issue). Furthermore, we observe splice form IV expression in embryos prior to limb bud formation (Fig. 1B), which is consistent with a role for this transcript in the early determinative events involved in limb patterning.

Expression of splice form IV is also observed at relatively high levels in the AER (Fig. 6), in addition to a new splice form that we have identified in limb ectoderm (Fig. 5). The consistency of this expression in the AER with the observed AER defect in $l d$ mutants suggests that one or both of these gene products are required for complete AER differentiation. This deficiency in the AER of $l d$ mutants has no apparent effect on proximaldistal limb patterning (Zeller et al. 1989), a well-established consequence of AER removal (Saunders 1948). Thus, the function of $l d$ in the AER is specific for the complete morphological differentiation of these cells because $1 d$ mutations do not disrupt all AER functions.

In addition to its expression in the developing limb, splice form IV is also observed throughout the embryo together with splice forms I, II, and III (Fig. 1). However, the known $1 d$ phenotypes indicate a functional requirement for the $1 d$ gene products only in the developing limb and kidney. Several possibilities could account for the discordance of the observed expression pattern of $1 d$ transcripts with the more restricted $l d$ phenotypes. If the known $1 d$ alleles represent the null phenotype, it is possible that partially redundant functions exist between $l d$ and other genetic loci in regions of $1 d$ expression apart from the limb and kidney (Maas et al. 1990 and references therein). Alternatively, expression of $l d$ in these other regions may not be essential, or phenotypic defects in these regions might be too subtle to have been noted.

It is not necessarily the case that the known $1 d$ alleles are null mutations. Nonetheless, two lines of evidence are consistent with this interpretation. First, the known ld mutations disrupt the coding region for most $1 d$ gene products (Maas et al. 1990), including splice forms I, II, and IV. The consequence of these mutations on the encoded formins is a predicted truncation of the carboxyl terminus involving a loss of $\sim 10 \%$ in the structure of these relatively large proteins (illustrated in Fig. 4). Second, all of the known ld alleles display fairly uniform limb and renal phenotypes, whereas variation in phenotype might have been expected from different partial loss-of-function mutations /Cupp 1960; Kleinebrecht et al. 1982; Woychik et al. 1985, 1990a; Zeller et al. 1989; Messing et al. 1990). On the other hand, these observations are also consistent with the possibility that the known $1 d$ alleles are partial loss-of-function mutations and that null alleles result in embryonic lethality. This interpretation is supported by the fact that the known mutations in this widely expressed gene have such a tissue-specific phenotype. The known $1 d$ mutants may represent the strongest possible viable $l d$ phenotype. Targeted mutagenesis in mouse embryonic stem cells (Gossler et al. 1986; Thomas and Capecchi 1987) should allow us to produce unequivocal null mutations to decide this point and to discern the potentially distinct roles of the different $l d$ gene products in vertebrate development.
Transcripts from the $1 d$ gene encode various distinct proteins, the formins (Woychik et al. 1990b). The complex expression patterns of these transcripts (Fig. 1), along with the striking differences in their deduced primary sequences, suggest that the different formins may have distinct functions. We have identified a transcript (splice form IV) expressed in the limb that encodes a potentially new formin (Fig. 2). The unique amino-terminal exon used in this transcript encodes an acidic domain, in contrast to the other formins, which have basic amino termini (Woychik et al. 1990b). Interestingly, Trumpp et al. (this issue) have recently cloned the chick Id transcript homologous to splice form IV, which revealed the conservation of the acidity of this domain (calculated pI 4.5, calculated charge at $\mathrm{pH} 7.0=-34$ ), although the absolute sequence conservation of this domain $(\sim 40 \%)$ is much lower than that of the carboxyterminal region $(\sim 80 \%)$. In addition, we have identified another splice form, encoding an as yet uncharacterized formin, which is expressed in limb ectoderm along with splice form IV (Fig. 5). Although we do not know whether these gene products act independently or whether they interact, it is intriguing to speculate that expression of different combinations of $1 d$ gene products may result in distinct $l d$ gene functions.

Molecular analysis of the $1 d$ transcripts presented in this work suggests an important role for the $1 d$ splice form that we have characterized in patterning of the anteroposterior axis of the limb and AER differentiation. Expression patterns of other candidate regulatory genes in the limb, such as homeo box, retinoic acid receptor, and growth factor genes, also suggest their involvement in limb patterning (for review, see Tabin 1991). Our identification of the transcripts from the $1 d$ locus involved in limb morphogenesis will allow the continued analysis of the function of $1 d$ gene products and their interaction with other genes in regulating limb development.

\section{Materials and methods}

Probes

Splice form-specific probes for forms I, II, and III were generated by PCR using the different clones described by Woychik et al. (1990b) as templates. The probe structures with reference to the original cDNA clone number and the nucleotide sequence of the probe borders are as follows: splice form I (clone 9) 19802180; splice form II (clone 7) 1980-2042 + 2338-2460; splice form III (clone 5) 1980-2042 + 2398-2460; splice form IV (clone 4) 1476-1775 (Fig. 3). Splice forms I, II, and III refer to the $1 d$ sequence with the GenBank accession number X53599 (Woychik et al. 1990b). The six other types of cDNA clones described by Woychik et al. (1990b) represent either differences in the $3^{\prime}$-untranslated region as a result of differential polyadenylation, or testis-specific transcripts, and were not used in our analysis.

PCR reactions with Taq polymerase (Cetus) were done according to the manufacturer's recommendations. The reaction products were cloned into Bluescript $\mathrm{pBS}(-\mid$ and sequenced to eliminate clones with PCR artifacts. The splice form IV probe is a subclone of the 612-bp EcoRI-PstI fragment from the 5' end of clone 4 (Woychik et al. 1990b) into pGEM-1, cut with PvuII to 
generate the 300-nucleotide-protected fragment shown above. A probe containing the 200-bp BamHI-HindIII fragment (1784 1983) of the 5' exon common to splice forms I, II, and III detects the expression of all three of these splice forms. The probe specific for the $5^{\prime}$ exon of splice form IV is a 517-bp BamHI-PstI fragment (421-937, Fig. 2; probe A, Fig. 3).

\section{Embryonic dissections}

Dissected embryos were derived from FVB/N matings. Gestational age was defined as the number of days p.c., such that the morning of vaginal plugging was designated day 0.5 as described by Rugh (1990). Embryos were also staged according to Rugh to eliminate any embryos that did not correspond to the appropriate developmental age. Dissection of limb buds and dissociations of limb ectoderm and mesenchyme were as described in Zeller et al. (1989). Dissociated ectodermal jackets and mesenchymal cones were sorted using a dissecting microscope, transferred to fresh Hanks balanced salt solution (HBSS) containing $10 \%$ serum, and resorted twice to ensure clean separations. All partially dissociated limb buds were discarded.

\section{Ribonuclease protection}

Total RNA was isolated using the method of Chirgwin et al. (1979). Ribonuclease protection was performed essentially as described by Krieg and Melton (1987). Probes were purified using Millipore Ultra-free spin filters. Radioactive probe $\left(1 \times 10^{5}\right.$ cpm) was hybridized to $20 \mu \mathrm{g}$ of total RNA except as noted for the limb ectoderm in Figure 5.

\section{cDNA library construction and screening}

Poly $(\mathrm{A})^{+}$RNA was prepared from gestational day 11.0 to day 11.5 prechondrogenic mouse limb buds (inbred strain FVB/N), using the methods of Chirgwin et al. (1979) and Aviv and Leder (1972), with two rounds of purification on oligo(dT)-cellulose (Collaborative Research). Random hexamer-primed doublestranded cDNA was prepared (Boehringer Mannheim cDNA synthesis kit) and fractionated by agarose gel electrophoresis to select for cDNAs $>600$ bp. Limb cDNA was modified by the addition of EcoRI adapters (Promega), ligated to vector arms (Lambda ZapII, Statagene), and packaged in vitro (Gigapack Gold II, Stratagene). Poly $(\mathrm{A})^{+}$RNA $(1.0 \mu \mathrm{g})$ yielded a library of $5 \times 10^{5}$ independent clones, which were plated without amplification and screened by filter hybridization following standard methods (Sambrook et al. 1989).

\section{Sequence analysis}

Sequence of both strands of the largest and 5 -most splice form IV cDNA, plus 250-300 bp of each end of the other cDNA clones, was determined by dideoxy chain termination using $\mathrm{T} 7$ DNA polymerase (Pharmacia). A genomic subclone containing this $5^{\prime}$ exon was also sequenced to verify this unique region, which is not present in the previously published sequence (Woychik et al. 1990b). Computer-assisted sequence analysis was done with software from the Genetics Computer Group, University of Wisconsin (Madison). The sequence is deposited in GenBank under accession number X62379.

\section{RNase $H$ mapping}

Five micrograms of poly $(\mathrm{A})^{+}$RNA from salivary gland or whole day-10.5 p.c. embryos was hybridized to $20 \mathrm{ng}$ of a 200-bp $1 d 3^{\prime}$ region PstI restriction fragment in $30 \mu \mathrm{l}$ of $50 \%$ formamide, 0.4
$\mathrm{M} \mathrm{NaCl}, 0.04 \mathrm{M}$ PIPES (pH 6.4), and $1 \mathrm{mM}$ EDTA at $55^{\circ} \mathrm{C}$ overnight, after heating for $10 \mathrm{~min}$ at $90^{\circ} \mathrm{C}$. The samples were diluted to $200 \mu \mathrm{l}$ with $0.3 \mathrm{M} \mathrm{NaAc}(\mathrm{pH} 5.2)$ and precipitated with 2.5 volumes of ethanol. The washed and dried precipitates were resuspended in $20 \mathrm{~mm}$ Tris- $\mathrm{HCl}$ (pH 7.5), $10 \mathrm{mM} \mathrm{MgCl}, 100 \mathrm{~mm}$ $\mathrm{KCl}, 0.1 \mathrm{~mm}$ dithiothreitol, and $5 \%$ sucrose and incubated for 30 min with 1 unit of RNase $\mathrm{H}$ (BRL) at $37^{\circ} \mathrm{C}$ (Irminger et al. 1987). The digestion was terminated by the addition of EDTA to 10 $\mathrm{mM}$, extracted with phenol-chloroform, and ethanol-precipitated. The digestion products were analyzed by Northern blot hybridization after electrophoresis in formaldehyde-agarose gels. Filters were hybridized to random hexamer-labeled restriction fragments as described (Sambrook et al. 1989).

\section{Cosmid cloning}

A cosmid library was constructed using $35-$ to $50-\mathrm{kb}$ fragments of BALB/c liver DNA generated by partial digestion with Sau3A, phosphatase treatment, and fractionation through two rounds of salt gradient ultracentrifugation. The vector was modified from the double COS site vector C2RB (Bates and Swift 1983) to contain RNA polymerase promoters and NotI sites flanking the BamHI cloning site and internal to the flanking EcoRI sites. Vector was cut with SmaI, phosphatased, and cut with BamHI. One microgram of vector was ligated to $0.5 \mu \mathrm{g}$ of genomic insert DNA in $5 \mu$ l. In vitro packaging (Gigapack XL, Stratagene) of 1 $\mu l$ of the ligation yielded $4 \times 10^{5} \mathrm{CFU}$, which were screened directly without amplification.

\section{In situ hybridization}

Day 10.5 p.c. embryos were fixed for $1-4 \mathrm{hr}$ in $4 \%$ paraformaldehyde, embedded in paraffin, cut into $2-\mu \mathrm{m}$ sections, and placed on gelatin-coated microscope slides prior to hybridization. Synthesis of ${ }^{35} \mathrm{~S}$-labeled riboprobes was from templates linearized to yield sense or anti-sense versions of the 517-bp BamHI-PstI fragment (probe A in Fig. 3) subcloned into Bluescript II KS $(+)$. Sections were pretreated, hybridized, and washed essentially as described by Wilkinson et al. (1987), with some modifications (Sassoon et al. 1988). Slides were dipped in emulsion (Kodak NTB-2) and exposed for 14-21 days before developing.

\section{Acknowledgments}

We are grateful to T. Vogt, R. Maas, and others in the Leder laboratory for helpful discussions during the course of this work, especially R. Zeller and R. Woychik. We appreciate the reagents and technical help provided by $R$. Chaillet (ES RNA); $P$. Gentile (oligonucleotide synthesis); and H.-G. Simon (in situ hybridization advice). We also thank $M$. Grusby and the entire Leder laboratory for comments on this manuscript, with special thanks to M. Shen, C. Tabin, and J. Flanagan for many critical discussions. This work was supported in part by a grant from E.I. DuPont de Nemours Co., Inc..

The publication costs of this article were defrayed in part by payment of page charges. This article must therefore be hereby marked "advertisement" in accordance with 18 USC section 1734 solely to indicate this fact.

\section{References}

Aviv H. and P. Leder. 1972. Purification of biologically active globin messenger RNA by chromatography on oligo- 
thymidylic acid-cellulose. Proc. Natl. Acad. Sci. 69: 14081412.

Bates, P.F. and R.A. Swift. 1983. Double cos site vectors: Simplified cosmid cloning. Gene 26: 137-146.

Chirgwin, J.M., A.E. Pryzbyla, R.J. MacDonald, and W.J. Rutter. 1979. Isolation of biologically active ribonucleic acid from sources enriched in ribonuclease. Biochemistry 18: 5294 5299.

Cupp, M.B. 1960. Mouse Newsl. 22: 50.

Doetschman, T.C., H. Eistetter, M. Katz, W. Schmidt, and R. Kemler. 1985. The in vitro development of blastocyst-derived embryonic stem cell lines: Formation of visceral yolk sac, blood islands and myocardium. J. Embryol. Exp. Morphol. 87: 27-45.

Fallon, J.F., D.A. Rowe, J.M. Frederick, and B.K. Simandl. 1983. Studies on epithelial-mesenchymal interactions during limb development. In Epithelial-mesenchymal interactions in development (ed. R.H. Sawyer and J.F. Fallon), pp. 3-25. Praeger Scientific, New York.

Globus, M. and S. Vethamany-Globus. 1976. An in vitro analogue of early chick limb bud outgrowth. Differentiation 6: 91-96.

Gossler, A., T. Doetschman, R. Korn, E. Serfling, and R. Kemler. 1986. Transgenesis by means of blastocyst-derived embryonic stem cell lines. Proc. Natl. Acad. Sci. 83: 9065-9069.

Grueneberg, H. 1963. The pathology of development. A study of inherited skeletal disorders in animals. Blackwell Scientific Publications, Oxford, England.

Irminger, J.-C., K.M. Rosen, R.E. Humbel, and L. Villa-Komaroff. 1987. Tissue-specific expression of insulin-like growth factor II mRNAs with distinct 5' untranslated regions. Proc. Natl. Acad. Sci. 84: 6330-6334.

Kelley, R.O. and J.F. Fallon. 1981. The developing limb: An analysis of interacting cells and tissues in a model morphogenetic system. In Morphogenesis and pattern formation. (ed. T.G. Connelly et al.), pp. 49-85. Raven Press, New York.

Kleinebrecht, J., J. Selow, and W. Winkler. 1982. The mouse mutant limb-deformity (ld). Anat. Anz. 152: 313-324.

Krieg, P.A. and D.A. Melton. 1987. In vitro synthesis with SP6 RNA polymerase. Methods Enzymol. 155: 397-415.

Lyon, M.F. and A.G. Searle. 1989. Genetic variants and strains of the laboratory mouse, 2nd ed. Oxford University Press, Oxford, England.

Maas, R.L., R. Zeller, R.P. Woychik, T.F. Vogt, and P. Leder. 1990. Disruption of formin-encoding transcripts in two mutant limb deformity alleles. Nature 346: 853-855.

Martin, P. 1990. Tissue patterning in the developing mouse limb. Int. J. Dev. Biol. 34: 323-336.

Messing, A., R.R. Behringer, J.R. Slepak, G. Lemke, R.N. Palmiter, R.L. Brinster. 1990. Insertional mutation at the LD locus (again!) in a line of transgenic mice. Mouse Newsl. 87: 107.

Reuss, C. and J.W. Saunders Jr. 1965. Inductive and axial properties of prospective limb bud mesoderm in the early chick embryo. Am. Zool. 5: 214.

Rowe, D.A. and J.F. Fallon. 1981. The effect of removing posterior apical ectodermal ridge of the chick wing and leg on pattern formation. J. Embryol. Exp. Morphol. 65: 309-325.

Rugh, R. 1990. The mouse. Its reproduction and development. Oxford University Press, Oxford, England.

Sambrook, J., E.F. Fritsch, and T. Maniatis. 1989. Molecular cloning: A laboratory manual, 2nd ed. Cold Spring Harbor Laboratory Press, Cold Spring Harbor, New York.

Sassoon, D.A., I. Garner, and M. Buckingham. 1988. Transcripts of alpha-cardiac and alpha-skeletal actins are early markers for myogenesis in the mouse embryo. Development
104: 155-164

Saunders, J.W. Jr. 1948. The proximo-distal sequence of origin of the parts of the chick wing and the role of the ectoderm. $J$. Exp. Zool. 108: 363-403.

. 1977. The experimental analysis of chick limb bud development. In Vertebrate limb and somite morphogenesis (ed. D.A. Ede, J.R. Hinchliffe, and M. Balls), pp. 1-24. Cambridge University Press, Cambridge, England.

Saunders, J.W. Jr. and M.T. Gasseling. 1968. Ectodermal-mesenchymal interactions in the origin of limb symmetry. In Epithelial-mesenchymal interactions (ed. R. Fleischmajer and R.E. Billingham), pp. 78-97. Williams and Wilkins, Baltimore, MD.

Solursh, M., C.T. Singley, and R.S. Reiter. 1981. The influence of epithelia on cartilage and loose connective tissue formation by limb mesenchyme cultures. Dev. Biol. 86: 471-482.

Tabin, C.J. 1991. Retinoids, homeoboxes and growth factors: Toward molecular models for limb development. Cell 66: $199-217$.

Thomas, K.R. and M.R. Capecchi. 1987. Site-directed mutagenesis by gene targeting in mouse embryo-derived stem cells. Cell 51: 503-512.

Tickle, C. 1980. The polarizing region and limb development. In Development in mammals (ed. M.H. Johnson), vol. 4, pp. 101-136. Elsevier/North-Holland Biomedical Press, Amsterdam, The Netherlands.

Wilkinson, D.G., J.A. Bailes, and A.P. McMahon. 1987. A molecular analysis of mouse development from 8 to 10 days post coitum detects changes only in embryonic globin expression. Development 99: 493-500.

Wolpert, L. 1969. Positional information and the spatial pattern of cellular differentiation. $/$. Theor. Biol. 25: 1-47.

Woychik, R.P., T.A. Stewart, L.G. Davis, P. D'Eustachio, and P. Leder. 1985. An inherited limb deformity created by insertional mutagenesis in a transgenic mouse. Nature 318: 3640.

Woychik, R.P., W.M. Generoso, L.B. Russell, K.T. Cain, N.L.A. Cacheiro, S.J. Bultman, P.B. Selby, M.E. Dickinson, B.L.M. Hogan, and J.C. Rutledge. 1990a. Molecular and genetic characterization of a radiation-induced structural rearrangement in mouse chromosome 2 causing mutations at the limb deformity and agouti loci. Proc. Natl. Acad. Sci. 87: 2588-2592.

Woychik, R.P., R.L. Maas, R. Zeller, T.F. Vogt, and P. Leder. 1990b. "Formins": Proteins deduced from the alternative transcripts of the limb deformity gene. Nature 346: 850853.

Zeller, R., L. Jackson-Grusby, and P. Leder. 1989. The limb deformity gene is required for apical ectodermal ridge differentiation and anteroposterior limb pattern formation. Genes \& Dev. 3: 1481-1492.

Zwilling, E. 1956a. Interactions between limb bud ectoderm and mesoderm in the chick embryo. I. Axis establishment. J. Exp. Zool. 132: 157-172.

. 1956b. Interactions between limb bud ectoderm and mesoderm in the chick embryo. IV. Experiments with a wingless mutant. J. Exp. Zool. 132: 241-253.

Zwilling, E. and L. Hansborough. 1956. Interactions between limb bud ectoderm and mesoderm in the chick embryo. III. Experiments with polydactylous limbs. I. Exp. Zool. 132: 219-239. 


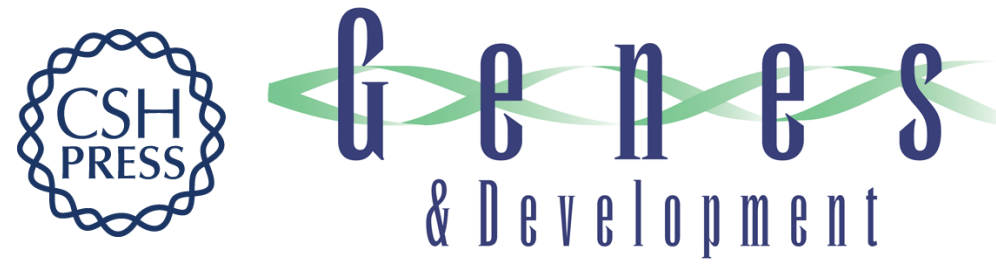

\section{A variant limb deformity transcript expressed in the embryonic mouse limb defines a novel formin.}

$L$ Jackson-Grusby, A Kuo and $P$ Leder

Genes Dev. 1992, 6:

Access the most recent version at doi:10.1101/gad.6.1.29

References This article cites 29 articles, 7 of which can be accessed free at:

http://genesdev.cshlp.org/content/6/1/29.full.html\#ref-list-1

License

Email Alerting

Service

Receive free email alerts when new articles cite this article - sign up in the box at the top right corner of the article or click here.

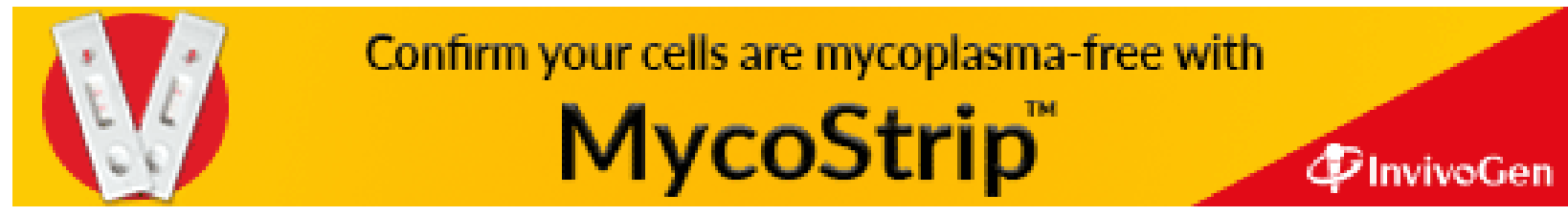

